\title{
Aspectos epidemiológicos do uso de drogas entre estudantes do ensino médio no Município de Palhoça 2003
}

\author{
Epidemiologic aspects of drug use among $5^{\text {th }}$ \\ grade to $12^{\text {th }}$ grade students in the city \\ of Palhoça 2003
}

Sérgio Luiz Sanceverino 1

José Luiz Crivelatti de Abreu 2

\footnotetext{
1 Instituto de Psiquiatria do Estado de Santa Catarina. Rua Geral Colônia Santana s/n, 88123-000, São José SC. sergioluis@unisul.br 2 Programa de Pós-Graduação da Universidade do Sul de Santa Catarina.
}

\begin{abstract}
The main objectives of this work were to investigate the prevalence of drug use among 5th grade to 12th grade students in a small city in the south of Brazil and to verify if they use any kind of health service. The study was carried out in nine out of a total of ten public and private schools. The sample consisted of 889 (18,10\%) students out of a total of 4,909 students, 4,139 $(84,31 \%)$ in public schools and $770(15,69 \%)$ in private ones. The participants answered a questionnaire that followed a model used by Galduróz, N oto and Carlini (1997) in the 4th Study of Drug U se Among Elementary and $\mathrm{H}$ igh School Students in Ten Brazilian Capital Cities. The collected data was inserted in the Epi Info 6.04d software and we have observed that the most used drugs were alcohol, tobacco, inhalants, marijuana, and amphetamines. With the exception of alcohol and tobacco, the most used drugs among women were inhalants, marijuana, tranquilizers, amphetamines and sedatives. Among men the most used drugs were inhalants, marijuana, amphetamines, tranquilizers and cocaine. Drug use is more frequent among older students and those who attend classes at night. There was no significant consumption difference among students of different socioeconomic levels. In addition, we have compared our results with other researches. Key words Drug use, Schools, epidemiology, Collective health
\end{abstract}

Resumo Este estudo teve como objetivo conhecer a prevalência do uso de drogas entre estudantes do ensino médio em um município do Sul do Brasil, em 2003, além de averiguar se houve utilização de algum serviço de saúde. Foi realizado em nove - entre dez - escolas de ensino médio da rede pública e particular. A amostra foi de 889 (18, 1\%) em um universo de 4.909 estudantes $4.139(84,3 \%)$ da rede pública e $770(15,7 \%)$ da rede particular. Os participantes responderam a questionário que seguiu o modelo utilizado por Galduróz, N oto e Carlini no IV Levantamento sobre o U so de Drogas entre Estudantes de 10 e $2 \underline{0}$ graus em Dez Capitais Brasileiras. Os dados foram inseridos no Programa Epi Info 6.04d e observou-se que as drogas de maior prevalência foram o álcool, o tabaco, os inalantes, a maconha eas anfetaminas. Excetuando-se o álcool e o tabaco, as drogas mais consumidas entre as mulheres foram os inalantes, a maconha, os tranqüilizantes, as anfetaminas e os sedativos; e entre os homens, os inalantes, a maconha, as anfetaminas, os tranqüilizantes e a cocaína. 0 consumo de drogas também é maior entre estudantes de maior faixa etária e os que freqüentam as aulas no período noturno. Não se verificaram diferenças significativas entre os níveis socioeconômicos. Foram feitas comparações com outras pesquisas.

Palavras-chave U so de drogas, Ensino médio, Epidemiologia, Saúde coletiva 


\section{Introdução}

Quando se fala em uso de drogas, as pessoas demonstram medo e preconceito... Drogas... algo de que se deseja distância, pois culpa, angústia e desespero são sentimentos de muitas famílias que convivem com usuários de drogas. Muitos pais protegem os filhos para que não entrem em contato com tais substâncias, porém se esquecem que na maioria das vezes é na própria família que as crianças efetuam seu primeiro contato com elas.

Geralmente os jovens iniciam suas experiências com as drogas consideradas lícitas, como 0 álcool e o tabaco em seus ambientes familiares. Após, podem recorrer às ilícitas para aumentar o seu prazer, procurar outras emoções ou fugir de seus problemas, sendo os inalantes e a maconha as drogas mais consumidas nesta fase (Bucher, 1992)

As discussões sobre 0 assunto são influenciadas pela paixão e, ainda que ocorram debates nos meios de comunicação e sejam evidenciados números preocupantes sobre o consumo de drogas, raramente são disponibilizados dados confiáveis de modo a auxiliar na prevenção do problema.

Ao observar a história da humanidade, nota-se que o homem sempre conviveu com o uso de drogas, sem que isto fosse motivo de alarme social. Os seres humanos sempre buscaram 0 prazer, o alívio da ansi edade e outras alterações do nível de consciência através de ingestão de várias substâncias naturais ou sintéticas (Colasanti et al., 1996). Durante séculos, certas plantas têm sido usadas para trazer e obter benefícios para o corpo, mente e espírito.

As substâncias psicoativas foram, e ainda são, consumidas em diversas épocas e culturas com finalidades terapêuticas, religiosas ou lúdicas. Elas estão presentes desde a Antigüidade.

A preocupação que mobiliza a sociedade no Brasil se deve à enorme e crescente disseminação do consumo de drogas, aos crimes hediondos cometidos por seus usuários e pela idade cada vez mais precoce das pessoas que se tornam dependentes delas, especialmente as ilícitas, mas, também, aquelas com comércio autorizado pelas instituições.

Paraa Organização Mundial da Saúde(OMS), droga é qualquer substância natural ou sintética que, administrada por qualquer via no organismo, afeta sua estrutura ou função, ea pessoa com menor possibilidade de usar drogas é aquela que ébem informada, bem integrada na família e sociedade, com boa saúde e qualidade de vida satisfatória e com difícil acesso às drogas.

O uso e abuso de drogas, lícitas ou ilícitas, representa um grave problema de saúde pública e coletiva. Produz enormes e indesejáveis repercussões sociais, culturais e econômicas.

Segundo Bernardo (1995), comparado com o nível do empregado médio, um típico usuário "recreativo" de drogas na força de trabal ho de hoje apresenta 2,2 vezes mais a probabilidade de solicitar demissão antecipada ou tempo de folga, 2,5 vezes mais a probabilidade de ausentar-se por oito dias ou mais do trabal ho, 3 vezes maior probabilidade de se atrasar para o trabalho em comparação com os demais trabalhadores, entre outras situações no trabalho.

Outros estudos, realizados em 1993, pela Federação das Indústrias de São Paulo, revelaram que entre $10 \%$ e $15 \%$ dos empregados têm problemas com dependência ao uso de drogas, fato que acarreta três vezes mais licenças médicas que outras doenças, entre $15 \%$ e $30 \%$ de todos os acidentes de trabal ho, $50 \%$ a mais de absenteísmo e licenças médicas (Senad, 2003).

0 uso de drogas entre adolescentes causa preocupação nos dias atuais. Estudos realizados em várias cidades brasileiras têm buscado averiguar a prevalência do consumo de drogas entre os jovens, problema que vem ocorrendo em muitos lugares. De fato, a O rganização PanAmericana de Saúde destinou um número especial (OPAS, 1989) de sua revista mensal a estudos realizados sobre o consumo de drogas nas Américas.

Muza e colaboradores (1997), ao estudarem o consumo de substâncias psicoativas em escolares na cidade de Ribeirão Preto (SP), chegaram aos seguintes resultados: taxas de uso na vida para o álcool de $88,9 \%$, para o tabaco de $37,7 \%, 31,1 \%$ para os solventes, $10,5 \%$ para os medicamentos, 6,8\% para maconha, 2,7\% para cocaína, 1,6\% para alucinógenos e $0,3 \%$ para opiáceos.

No Distrito Federal, um estudo de Godoi et al. (1988), em que participaram alunos de primeiro e segundo graus da rede de ensino privada, mostra que o uso de substâncias psicoativas na vida chega às taxas de 67,2\% para o álcool, $28,7 \%$ para o tabaco, $13,9 \%$ para inalantes, $6,1 \%$ para maconha e $6,7 \%$ para tranqüilizantes.

Na cidade de Cuiabá, Souza e M artins (1995) levantaram perfil epidemiológico do uso de drogas entre estudantes de 10 e 20 graus da rede estadual, e encontraram maior proporção de usuários com idade acima de 18 anos, melhor 
poder aquisitivo, com maior número de faltas escolares. Excetuando-se o álcool e o tabaco, as substâncias mais freqüentemente usadas na vida pelos estudantes foram os solventes $(14,9 \%)$, os ansiolíticos (6,0\%), as anfetaminas $(4,8 \%)$, a maconha $(3,8 \%)$, os barbitúricos $(2,1 \%)$ e a cocaína $(1,8 \%)$.

O levantamento de consumo de drogas entre estudantes das capitais de 10 dos Estados brasileiros, realizado mais recentemente pelo Centro Brasileiro de Informações sobre Drogas Psicotrópicas (Galduróz et al. 1997) apresenta, também, indicações preocupantes. Cerca de $24,7 \%$ dos participantes haviam feito uso de drogas alguma vez na vida, excetuando-se álcool e tabaco. 0 uso de maconha aumentou em todas as capitais pesquisadas e em nove delas os solventes aparecem como a droga mais usada, sendo a segunda mais usada na capital restante. A maconha aparece como a segunda droga consumida ocupando o primeiro lugar em uma capital, o segundo em seis capitais e o terceiro em uma capital. Em terceiro lugar na preferência dos participantes ficaram os ansiolíticos e as anfetaminas.

Baus et al. (2002), em estudo realizado em uma escola pública de Florianópolis, encontraram os seguintes resultados: a prevalência de uso de maconha foi de $19,9 \%$, de solventes $18,2 \%$, de anfetamínicos $8,4 \%$, deálcool $86,8 \%$, de tabaco $41,8 \%$, de ansiolíticos 5,6\%, de cocaína 2,9\% e de alucinógenos $2,7 \%$.

O uso de drogas é responsável também por vários problemas de saúde e considerado um dos maiores problemas de saúde pública em vários países. Além dos prejuízos que causa no indivíduo, os custos para o serviço de saúde também são altos.

De fato, cerca de $32 \%$ dos leitos hospitalares em psiquiatria e $40 \%$ das consultas psiquiátricas são destinados a pacientes com abuso de álcool. Além disso, 75\% dos acidentes de trânsito fatais e $39 \%$ das ocorrências policiais estavam associados ao uso de bebidas alcoólicas (Bucher, 1992).

Oliveira e Luís (1996), por sua vez, corroboram esses dados ao afirmarem que o álcool está relacionado com 1,5 milhões de acidentes de trânsito por ano e 39\% de todas as ocorrências policiais. Apresentam também os dados do Detran de Porto Alegre, nos quais se apurou que em metade dos acidentes de trânsito, de modo geral, e em $75 \%$ dos acidentes de trânsito com vítimas fatais havia pelo menos uma pessoa al coolizada.
De 1995 a 1997, mais de 310 milhões de reais foram gastos em internações decorrentes do uso abusivo e da dependência de álcool, sendo que o alcoolismo ocupava o quarto lugar no grupo das doenças que mais incapacitam, considerando a prevalência global (Senad, 2003).

Os casos de Aids entre os usuários de drogas injetáveis vêm apresentando um aumento expressivo. Em 1985 este número representava 2,7\% do total dos casos, já em 1990 chegou a $18,2 \%$ e atualmente, cerca de $25 \%$ dos casos de Aids notificados ao M inistério da Saúde estão relacionados ao uso de drogas injetáveis. Esta forma de transmissão do HIV é responsável também pelo aumento do número de casos de Aids entre as mulheres, parceiras sexuais dos usuários, e, consequentemente da Aids pediátrica (Senad, 2003).

Outro fato a ser considerado é a violência. 0 uso abusivo de álcool expõe as pessoas a maiores índices de agressões, principalmente a doméstica realizada contra as mulheres e crianças.

Este estudo teve como objetivo conhecer a prevalência do uso de drogas entre estudantes do ensino médio no município de Palhoça.

Palhoça é um município localizado no litoral de Santa Catarina, distante aproximadamente 20 quilômetros ao sul de Florianópolis. Conta atualmente com uma população de 102.286 pessoas, 51.207 homens e 51.079 mulheres dos quais 95,3\% residem na área urbana e 4,7\% ocupam a área rural do município, com uma taxa de crescimento anual de 5,95\% (IBGE, 2000). É o décimo município catarinense em número de habitantes e se caracteriza por grande diversidade de atividade econômica, de costumes, origens étnicas, bem como por festividades religiosas e tradicionais que encontram grande interesse público.

O município foi colonizado por imigrantes açorianos, mas vem recebendo população rural oriunda de vários pontos do Estado, em busca de emprego. Tal fato gerou problemas, com tendências ao crescimento desordenado e falta de infra-estrutura urbana e, em decorrência, um processo de favelização e criação de loteamentos irregulares.

\section{Método}

O estudo se caracterizou como transversal e descritivo. Foi realizado entre estudantes do ensino médio das escolas do município, que possui 10 escolas, seis públicas e quatro parti- 
culares. Estudantes de nove escolas participaram, pois em uma escola particular não foi possível realizar devido ao cronograma das aulas.

Foram realizadas visitas prévias às escolas, quando foi apresentado o projeto com a entre ga de uma cópia do mesmo aos gestores das escolas. Aproveitou-se o momento para efetuar o levantamento do número de turmas do ensino médio, indicações do turno em que funcionavam e do número de estudantes em cada uma delas.

Percebeu-se que o tema da pesquisa era de interesse de todos os gestores. Houve relatos sobre dificuldades para trabal har com 0 assunto e, também, sobre medidas adotadas para diminuir o envolvimento com as drogas.

Para a seleção da amostra foi utilizado o módulo Statcalc, do Programa Epi Info 6.04d, com base em uma população estimada em 5.000 estudantes, com prevalência esperada de $2,00 \%$, erro de $1,00 \%$ e $95 \%$ de confiança. Chegou-se ao total de 654 estudantes e optou-se por efetuar coleta de dados com, no mínimo, 800 estudantes prevendo possíveis erros de preenchimentos e recusas em participar da pesquisa. Para seleção da amostra, consideraramse aspectos como o caráter público ou particular da instituição, o turno de funcionamento (diurno ou noturno) e eqüidade na proporção do número total de estudantes. A amostra representou $18,15 \%$ do total da população dos estudantes no município. 0 processo de amostragem foi estratificado por escolas e turno freqüentado pelos estudantes, e organizados em conglomerados por turmas abordadas.

No levantamento chegou-se a um total de 4.909 estudantes, 4.139 (84,3\%) eram das escolas públicas, $2.037(49,2 \%)$ do período diurno e 2.102 (50,8\%) do período noturno. Dos 770 $(15,7 \%)$ estudantes das escolas particulares, $520(67,5 \%)$ estavam no período diurno e 250 (32,5\%) no período noturno. Dos participantes da pesquisa, 348 freqüentavam escolas públicas durante o período diurno, 390 as freqüentavam no período noturno. Nas escolas particulares foram 111 estudantes do período diurno e 42 do período noturno.

As escolas públicas estavam localizadas em vários bairros da cidade, favorecendo o acesso dos estudantes de diversos bairros. A escola pública localizada no centro da cidade recebe, singularmente, estudantes de vários bai rros em que não há ensino médio. As escolas particulares, por outro lado, estão concentradas no cen- tro da cidade o que favorece o deslocamento dos estudantes.

Duas das escolas públicas são freqüentadas por cerca de $94 \%$ dos estudantes do período diurno. A maior oferta de vagas no período noturno é devida ao interesse em gerar oportunidades para que os estudantes possam trabaIhar durante o dia.

No que se refere às características sociode mográficas dos participantes da pesquisa, a tabela 1 apresenta dados que denotam uma pequena superioridade no número de estudantes do sexo feminino ( $54,1 \%$ ), e que $44,8 \%$ dos participantes eram do sexo masculino e apenas $1,1 \%$ não responderam a questão quanto ao gênero.

As idades variaram de 14 anos até 50 anos, com média de 17,1 anos. M ostra que cerca de $72 \%$ deles apresentam idades inferiores a 18 anos, porém vale ressaltar o número de estudantes com mais de 20 anos, o que sugere a volta de al gumas pessoas para a escola, buscando a melhor qualificação profissional.

Os dados coletados preliminarmente mostram que dentre os participantes da pesquisa, $51,9 \%$ haviam sofrido reprovação em uma ou mais vezes.

E, quanto ao nível socioeconômico, perce-

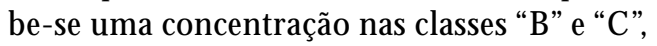
abrangendo $78 \%$ dos participantes. Percebe-se o afastamento das escolas por parte da classe economicamente menos favorecida: apenas $0,7 \%$ dos estudantes se enquadraram na classe "E", mesmo a pesquisa sendo realizada em instituições públicas.

A coleta de dados começou a ser feita após se ter as relações das turmas e de estudantes. Em seguida, procedeu-se ao sorteio das turmas para a pesquisa e buscaram-se entendimentos com os gestores para a aplicação do instrumento de coleta de dados. Em caso de impossibilidade da participação de uma dada turma sorteada, haveria sua substituição.

Nas turmas diurnas das escolas públicas, a pesquisa foi concentrada em duas escolas que detinham, juntas, aproximadamente $93 \%$ dos estudantes deste período, evitando-se coletar dados em duas outras escolas com turmas no período diurno, pois possuíam pequeno número de estudantes. No período noturno a pesquisa foi realizada em todas as escolas.

No que se refere às turmas diurnas das escolas particulares, a pesquisa foi realizada em dois estabelecimentos, um deles com duas turmas. No período noturno, a coleta de dados foi 


\begin{tabular}{|c|c|c|c|}
\hline Características & & $\mathbf{N}$ & $\%$ \\
\hline \multirow[t]{4}{*}{ Sexo } & Feminino & 481 & 54,1 \\
\hline & Masculino & 398 & 44,8 \\
\hline & Não-informado & 10 & 1,1 \\
\hline & Total & 889 & 100,0 \\
\hline \multirow[t]{6}{*}{ Faixa etária (anos) } & 14 a 15 & 222 & 24,9 \\
\hline & 16 a 17 & 418 & 47,0 \\
\hline & 18 a 19 & 126 & 14,2 \\
\hline & 20 e mais & 90 & 10,2 \\
\hline & Não-informado & 33 & 3,7 \\
\hline & Total & 889 & 100,0 \\
\hline \multirow[t]{3}{*}{ Período } & Diurno & 457 & 51,4 \\
\hline & Noturno & 432 & 48,6 \\
\hline & Total & 889 & 100,0 \\
\hline \multirow[t]{8}{*}{ Fase (semestre letivo) } & Primeira & 91 & 10,2 \\
\hline & Segunda & 389 & 43,8 \\
\hline & Terceira & 108 & 12,2 \\
\hline & Quarta & 150 & 16,9 \\
\hline & Quinta & 62 & 6,9 \\
\hline & Sexta & 78 & 8,8 \\
\hline & Não-informado & 11 & 1,2 \\
\hline & Total & 889 & 100,0 \\
\hline \multirow[t]{6}{*}{ Nível socioeconômico } & $A$ & 116 & 13,0 \\
\hline & B & 310 & 34,9 \\
\hline & $\mathrm{C}$ & 383 & 43,1 \\
\hline & $D$ & 74 & 8,3 \\
\hline & $\mathrm{E}$ & 6 & 0,7 \\
\hline & Total & 889 & 100,0 \\
\hline
\end{tabular}

realizada na única escola em que havia turmas.

A coleta de dados foi realizada pelo pesquisador e um auxiliar treinado para a realização do estudo.

A coleta dos dados foi realizada durante uma semana, entre os dias 10 e 5 de setembro, de 2003, visitando-se duas escolas por dia em diferentes turnos, com a preocupação de evitar que comentários sobre a pesquisa pudessem prejudicar seu andamento.

Depois de agendada a visita, os pesquisadores compareciam às escolas e se dirigiam às turmas sorteadas, às quais eram apresentados pelos gestores da escola. Os gestores então se retiravam e os pesquisadores forneciam explicações sobre o estudo. Após a aceitação em participar, eram distribuídos os questionários e oferecidas orientações para o preenchimento. Toda a aplicação foi feita em sala de aula, coletivamente, sem a presença do professor.
Embora tenha sido informado aos participantes sobre a possibilidade de não participarem, não houve qualquer recusa e observou-se grande expectativa de parte dos estudantes.

Após o preenchimento, os questionários foram colocados em urnas para que o sigilo quanto à identidade dos respondentes fosse respeitado. 0 tempo médio de aplicação em cada turma foi de 45 minutos.

O questionário utilizado para a pesquisa seguiu o modelo utilizado por Galduróz et al. (1997) no IV Levantamento sobre o Uso de D rogas entre Estudantes de 1 으 e 2 o graus em 10 Capitais Brasileiras, resultante de uma adaptação efetuada por Carlini-Contrim et al., em 1989, a partir de um instrumento proposto pela O rganização M undial da Saúde e desenvolvido pela WHO - Research and Reporting Project on the Epidemiology of Drug Dependence. No caso do presente estudo, foram in- 
cluídas questões relativas ao uso de serviços de saúde (tratamento, auto-ajuda, internação) decorrentes de situações de emergência devido ao uso da(s) droga(s), ou busca de tratamento visando à cessação do uso. Trata-se de um questionário fechado, de autopreenchimento e sem identificação do aluno.

Foram aplicados 891 questionários, dos quais apenas dois $(0,22 \%)$ apresentaram erros em seu preenchimento e foram excluídos. Uma vez coletados, os dados foram inseridos no Programa Epi Info 6.04d.

Com referência às classes sociais, houve agrupamento dos participantes em duas classes, correspondendo às classes $A+B$ e $C+D+E$ do instrumento utilizado por Galduróz et al. em que se aplicou [...] a escala sócio-econômica da Associação Brasileira dos Institutos de Pesquisa de M ercado [...] que se baseia em itens de consumo eno grau de escolaridade do responsável pela família, para a classificação em classes A, B, C, D eE (1997).

$M$ ais além, os participantes foram distribuídos por gênero, faixa etária, turno de freqüência à escola e a categoria da instituição (pública ou particular).

Para levantar aspectos relacionados às quantidades do uso, este estudo atentou para "uso na vida", quando a pessoa utilizou droga psicotrópica pelo menos uma vez na vida e "uso freqüente" quando a pessoa utilizou droga psicotrópica duas ou mais vezes nos trintas dias que antecederam a pesquisa, para consumo de qualquer droga.

\section{Resultados}

Os resultados a seguir demonstrarão a prevalência do consumo de drogas entre os estudantes. Estarão divididos, a princípio, em "uso na vida", com indicadores quanto a "gênero", "faixa etária", "turno de funcionamento da turma", "categoria da escola" e "nível socioeconômico". Os dados serão apresentados de modo a preservar o sigilo quanto às instituições.

A tabela 2 mostra que a droga mais consumida entre os estudantes, o ál cool, possui um consumo equivalente entre os gêneros, mostrando-se preocupante entre as mulheres. $M$ ais além, nota-se que o álcool apresenta forte consumo entre os adolescentes.

O maior consumo de maconha, cocaína e inalantes entre os homens, por sua vez, coincide com os resultados de Galduróz et al. (1997), que indicam maior consumo dessas drogas en- tre homens nas dez capitais pesquisadas. Notase o predomínio do consumo de drogas ilícitas por parte de pessoas do sexo masculino. Esta tabela também confirma a preferência do consumo de tranqüilizantes pelas mulheres, fato observado em sete das capitais pesquisadas, duas da Região Sul.

O álcool com $91,9 \%$ e o tabaco com $42,5 \%$ foram as drogas mais utilizadas pelos estudantes. Estes números são superiores ao estudo realizado por Souza e M artins na cidade de Cuiabá com índices de 78,6\% para o álcool e 29,0\% para o tabaco. Foram, todavia, semelhantes aos obtidos em levantamento feito por M uza et al. realizado na cidade de Ribeirão Preto em 1997 que apresentou um índice de $88,9 \%$ para 0 álcool e de 37,7\% para o tabaco.

Percebe-se que, quanto às faixas etárias, 0 consumo de álcool não apresenta diferença significativa demonstrando a aceitação e a convivência com uso desta droga, relacionado a comemorações de diversas formas e à facilidade de acesso e aquisição. Diante desses dados, parece importante reconhecer que mesmo sendo proibida a venda de bebidas al coólicas para menores de 18 anos de idade, $71,5 \%$ deles indicaram já haver adquirido al guma bebida alcoólica. 0 vinho com $42,8 \%$ é a bebida preferida pelas mulheres e a cerveja ou chope com $45,1 \%$ a preferida pelos homens.

Com relação ao uso de tabaco, maconha, cocaína e anfetaminas há uma diferença significativa entre as faixas etárias, sendo estas substâncias consumidas por pessoas de maiores idades. 0 cigarro já foi consumido pelo menos uma vez na vida por $44,5 \%$ dos estudantes do sexo feminino e por $40,5 \%$ do sexo masculino, sendo que $72,6 \%$ afirmaram que começaram a fumar com 15 anos ou menos.

Fora o álcool e o tabaco, as drogas mais consumidas entre as mulheres foram respectivamente: os inalantes, a maconha, os tranqüilizantes, as anfetaminas e os sedativos; e entre os homens foram: os inalantes, a maconha, as anfetaminas, os tranqüilizantes e a cocaína. 0 uso de inalantes, de maconha e cocaína é maior entre os homens, sendo o uso de tranqüilizantes maior entre as mulheres.

A tabela 3 refere-se ao turno de freqüências às aulas eà categoria da escola. Com relação ao turno de freqüência às aulas, os estudantes do período noturno apresentam um maior consumo de álcool e, de modo mais significativo, 0 de tabaco, maconha e cocaína que os participantes matriculados em turmas diurnas. 
Tabela 2

Distribuição dos participantes em uso na vida segundo gênero e faixa etária (\%).

\begin{tabular}{lcccccc}
\hline Drogas & \multicolumn{3}{c}{ Sexo } & \multicolumn{3}{c}{ Faixa etária } \\
\cline { 2 - 7 } & Feminino & Masculino & $P$ & $14-17$ & 18 e mais & $P$ \\
\hline Álcool & 91,5 & 92,2 & 0,692 & 91,7 & 93,1 & 0,530 \\
Tabaco & 44,5 & 40,5 & 0,228 & 37,5 & 56,5 & $<0,001^{*}$ \\
Maconha & 14,1 & 20,1 & $0,019 *$ & 12,7 & 27,8 & $<0,001^{*}$ \\
Cocaína & 1,9 & 4,8 & $0,018 *$ & 1,9 & 6,5 & $<0,001^{*}$ \\
Anfetaminas & 8,7 & 6,0 & 0,130 & 6,6 & 11,1 & 0,030 \\
Inalantes & 15,4 & 20,9 & $0,035^{*}$ & 18,3 & 15,7 & 0,397 \\
Tranqüilizantes & 9,6 & 5,3 & $0,017^{*}$ & 7,7 & 7,9 & 0,919 \\
Anticolinérgicos & 0,4 & 1,0 & 0,290 & 0,6 & 0,9 & 0,647 \\
Sedativos & 2,3 & 0,8 & 0,070 & 1,1 & 3,2 & 0,031 \\
Dolantina/heroína & 0,8 & 0,5 & 0,558 & 0,5 & 1,4 & 0,163 \\
Xaropes & 0,2 & 0,5 & 0,458 & 0,2 & 0,5 & 0,418 \\
Alucinógenos/LSD & 1,2 & 1,3 & 0,984 & 1,1 & 1,4 & 0,724 \\
Periatin & 0,4 & 0 & 0,197 & 0,2 & 0 & 0,561 \\
\hline
\end{tabular}

* Diferença estatisticamente significativa entre os dois sexos (Teste do X2, $p<0,05$ )

\section{Tabela 3}

Distribuição dos participantes em uso na vida segundo turno das aulas e categoria das escolas (\%).

\begin{tabular}{lcccccc}
\hline Drogas & \multicolumn{5}{c}{ Turno } & \multicolumn{3}{c}{ Categoria } \\
\cline { 2 - 7 } & Diurno & Noturno & $\mathrm{P}$ & Particular & Pública & $\mathrm{P}$ \\
\hline Álcool & 90,1 & 93,8 & $0,046^{*}$ & 94,1 & 91,5 & 0,280 \\
Tabaco & 36,5 & 48,7 & $<0,001^{*}$ & 44,7 & 42,1 & 0,544 \\
Maconha & 11,4 & 22,2 & $<0,001^{*}$ & 18,4 & 16,4 & 0,547 \\
Cocaína & 1,8 & 4,8 & $0,009 *$ & 4,6 & 3,0 & 0,306 \\
Anfetaminas & 6,8 & 8,8 & 0,275 & 13,8 & 6,5 & $0,002 *$ \\
Inalantes & 17,6 & 18,2 & 0,797 & 23,7 & 16,8 & $0,045 *$ \\
Tranqüilizantes & 7,5 & 7,9 & 0,832 & 10,5 & 7,1 & 0,143 \\
Anticolinérgicos & 0,7 & 0,7 & 0,951 & 1,3 & 0,5 & 0,289 \\
Sedativos & 0,9 & 2,3 & 0,087 & 0 & 1,9 & 0,087 \\
Dolantina/heroína & 0,7 & 0,5 & 0,693 & 1,3 & 0,5 & 0,287 \\
Xaropes & 0,2 & 0,5 & 0,534 & 0,7 & 0,3 & 0,456 \\
Alucinógenos/LSD & 0,9 & 1,6 & 0,321 & 1,3 & 1,2 & 0,926 \\
Periatin & 0,2 & 0,2 & 0,973 & 0 & 0,3 & 0,512 \\
\hline
\end{tabular}

* Diferença estatisticamente significante entre os dois sexos (Teste do X2, $p<0,05$ )

Sobre o indicador "categoria da instituição", a tabela 3 mostra diferenças estatisticamente significativas do consumo de anfetaminas einalantes. 0 consumo maior dessas drogas foi apontado pelos estudantes das escolas particulares. Quanto às demais drogas, não há diferença estatisticamente significativa. As drogas mais consumidas nas duas categorias de instituição foram o álcool, o tabaco, os inalantes e a maconha, respectivamente. As anfetaminas e os tranqüilizantes ocuparam o quinto lugar na preferência dos estudantes das escolas particulares e das escolas públicas, respectivamente.
Na tabela 4 são apresentados os dados quanto ao indicador "classes sociais" e se observa maior consumo de álcool, anfetaminas e inalantes nas classes A+B. Q uanto ao consumo das demais drogas, não há diferença estatisticamente significativa., levando a supor que a inserção econômica não influencia de forma relevante o seu uso.

Com relação à procura de algum tipo de serviço de saúde devido ao uso de drogas os dados apurados mostram que $1,0 \%$ dos participantes já havia procurado atendimento em grupos de auto-ajuda, grupos religiosos. Aproximadamente $0,7 \%$, contudo, não continuaram 0 
Tabela 4

Distribuição dos participantes em uso na vida segundo a classe social (\%).

\begin{tabular}{lccc}
\hline Drogas & \multicolumn{3}{c}{ Uso na vida } \\
\cline { 2 - 4 } & $\mathrm{A}+\mathrm{B}$ & $\mathrm{C}+\mathrm{D}+\mathrm{E}$ & $\mathrm{P}$ \\
\hline Álcool & 95,3 & 88,8 & $<0,001^{*}$ \\
Tabaco & 40,4 & 44,5 & 0,215 \\
Maconha & 16,9 & 16,6 & 0,914 \\
Cocaína & 3,3 & 3,2 & 0,969 \\
Anfetaminas & 9,9 & 5,8 & $0,025 *$ \\
Inalantes & 21,6 & 14,7 & $0,007^{*}$ \\
Tranqüilizantes & 8,5 & 6,9 & 0,388 \\
Anticolinérgicos & 0,9 & 0,4 & 0,356 \\
Sedativos & 0,9 & 2,2 & 0,144 \\
Dolantina/heroína & 0,5 & 0,9 & 0,475 \\
Xaropes & 0,5 & 0,2 & 0,514 \\
Alucinógenos/lsd & 1,2 & 1,3 & 0,875 \\
Periatin & 0,5 & 0 & 0,140 \\
\hline
\end{tabular}

* Diferença estatisticamente significante entre os dois sexos (Teste do $X 2, p<0,05$ )

tratamento. A procura de um serviço de emergência foi citada por 0,9\% dos pesquisados, por "beberem demais", por "overdose" ou "ataques". Sobre a necessidade de internação apenas 0,2\% informaram que já estiveram internados.

\section{Discussão}

Por ser um questionário amplo, serão feitas a seguir mais al gumas análises dos dados obtidos através dos cruzamentos das informações. Será feita também uma comparação entre os estudos realizados nas três capitais da Região Sul do País.

A tabela 5 apresenta comparação entre os dados pertinentes ao indicador "uso na vida" de algum tipo de drogas entre os alunos de primeiro e segundo graus nas capitais da região Sul e do Brasil e do presente estudo.

N esta tabela percebe-se um número maior de usuários de álcool no município de Palhoça enquanto o de usuários de tabaco se faz de maneira semelhante entre as capitais e o município. 0 uso de maconha, por sua vez, acompanha o uso detectado nas capitais da região Sul, maior que o uso no Brasil.

Os solventes são mais consumidos no município, depois do álcool e do tabaco. Estes dados equiparam-se aos do estudo de Galduróz et al. (1997), que encontraram resultados semelhantes em nove das dez capitais que pesquisaram, exceção feita a Porto Alegre, onde o uso de solventes ficou em segundo lugar.
O uso de ansiolíticos e anfetamínicos foi o segundo maior. Há relatos de al guns dos participantes de que tais drogas foram oferecidas por seus pais, sem uma recomendação médica. Acredita-se também, que o uso de anfetamínicos tenha uma relação com o uso dos remédios para emagrecimento.

Os dados da tabela 5, finalmente, ainda mostram que o uso de cocaína é semelhante entre os usuários de Florianópolis e Curitiba, mas inferior ao consumo em Porto Alegre.

No que concerne aos dados colhidos por este estudo, não constantes nas figuras, é notório que, entre os solventes ou inalantes, as substâncias mais utilizadas pelos estudantes, que usuram esses produtos, foram o lança-perfume, com 50,0\%; a acetona, com $13,0 \%$ e a cola de sapateiro, com 9,7\%.

Entre os tranqüilizantes, a substância mais citada foi o diazepan, que foi utilizado por cerca de $40,0 \%$ dos participantes.

0 uso de substâncias alucinógenas também foi relatado pelos estudantes percebendo-se que mesmo com a substituição dos tipos de drogas, estas substâncias ainda estão sendo conseguidas e usadas, sendo o chá de cogumelo a substância com maior relato de uso.

Importante salientar que não houve relato do uso de drogas na forma injetável, o que torna mais importante os programas de redução de riscos para evitar que se inicie o uso.

Às indagações sobre os acontecimentos após a ingestão de bebidas alcoólicas, 31 estudantes 
Tabela 5

Comparação entre dados relativos aos indicadores “uso na vida” do presente estudo - Florianópolis, Curitiba, Porto Alegre e Brasil e (\%)*.

\begin{tabular}{lccccc}
\hline Drogas & \multicolumn{5}{c}{ Uso na vida } \\
\cline { 2 - 6 } & $\begin{array}{c}\text { Palhoça } \\
(\mathrm{N}=889)\end{array}$ & $\begin{array}{c}\text { Florianópolis } \\
(\mathrm{N}=478)\end{array}$ & $\begin{array}{c}\text { Curitiba } \\
(\mathrm{N}=1.430)\end{array}$ & $\begin{array}{c}\text { Porto Alegre } \\
(\mathrm{N}=1.374)\end{array}$ & $\begin{array}{c}\text { Brasil } \\
(\mathrm{N}=15.503)\end{array}$ \\
\hline Álcool & 90,77 & 86,8 & 79,6 & 77,0 & 75,9 \\
Tabaco & 42,20 & 41,8 & 41,0 & 44,1 & 32,8 \\
Maconha & 16,65 & 19,9 & 11,9 & 14,4 & 7,6 \\
Solventes & 17,66 & 18,2 & 14,4 & 12,4 & 13,8 \\
Ansiolíticos & 7,53 & 5,6 & 5,9 & 8,6 & 5,8 \\
Anfetamínicos & 7,41 & 8,4 & 5,9 & 6,6 & 4,4 \\
Cocaína & 3,15 & 2,9 & 2,8 & 4,5 & 2,0 \\
Alucinógenos & 1,24 & 2,7 & 1,7 & 1,0 & 0,8 \\
\hline
\end{tabular}

* Os dados relativos aos indicadores "uso na vida" foram colhidos de estudos realizados em Florianópolis (Baus).; Kupek, E; Pires M , 2002) em Curitiba, Porto Alegre e do Brasil (Galduróz JCF, Noto AR, Carlini EA, 1997).

$(3,5 \%)$ responderam que dirigiram veículos e, dentre esses, 10 com menos de 18 anos.

0 uso concomitante de maconha e cocaína foi afirmado por 26 (2,9\%) dos estudantes, 20 deles matriculados no período noturno, sendo 17 do sexo masculino.

Sobre a questão do relacionamento com 0 pai, $65,8 \%$ dos usuários de maconha e $65,5 \%$ dos de cocaína afirmaram que o seu relacionamento é bom ou ótimo. Apenas $6,7 \%$ e $10,3 \%$ respectivamente, avaliaram esse relacionamento como ruim ou péssimo.

É curioso notar que $32,5 \%$ dos participantes informaram já haver utilizado algum tipo de droga, excetuando-se o álcool e o tabaco, uma vez na vida.

\section{Considerações finais}

Esforços preventivos constituem-se em tarefas árduas, especialmente porque drogas de vários tipos estão incorporados à vida diária das pessoas, como éo caso do consumo em "horas do cafezinho" ou nas happy hours. 0 fato de a grande maioria das pessoas apenas se preocupar com o consumo das drogas ilícitas, esconde a amplitude da disseminação do uso dos mais diversos tipos de drogas. Com freqüência, a mídia veicula imagens em que as pessoas ingerem bebidas al coólicas para relaxar depois do trabalho ou, ainda, para relaxar e ter um sono reconfortante muitas usam tranqüilizantes "receitados" por leigos. E, para apresentar um corpo em boa forma muitos substituem a ginástica e a alimentação balanceada por medicamentos que diminuem o apetite e al iviam a ansiedade.

Parece importante ressaltar que, ainda que preocupados com o potencial consumo de drogas por parte dos filhos, muitos pais parecem ignorar que o primeiro contato com drogas ocorre nos lares e com o respaldo deles próprios, intencional ou inadvertidamente.

0 ensino médio é freqüentado, predominantemente, por adolescentes, época da vida em que ocorrem grandes descobertas e transformações. Período em que não são aceitas recomendações com bom grado e em que a maioria dos jovens busca a autonomia e atingir de imediato seus fins. Alguns desses adolescentes encontram nas drogas uma oportunidade para fugir de uma realidade adversa ou, talvez premidos pelos colegas, experimentá-las por curiosidade.

Segundo vários especialistas sobre o problema das drogas, o melhor combate ao uso indevido de drogas é a prevenção.

Carlini-Contrim (in Aquino, 1998) afirma que o enfoque de diminuição de riscos de uso de drogas na prática escolar viabiliza-se por cinco modelos básicos: conhecimento científi$\mathrm{co}$, em que se propõe o fornecimento de informações sobre drogas de modo imparcial e científico; educação afetiva, que defen de que jovens mais estruturados e menos vulneráveis do ponto de vista psicológico são menos propensos a se engajar num uso problemático de substâncias psicoativas; oferecimento de alternativas, em que se procura propiciar aos jovens oportunidades de crescimento pessoal, excitação, 
desafio e alívio do tédio; educação para a saúde dirigida a uma vida saudável, com orientações sobre alimentação adequada, atividades esportivas e recreativas, vida sexual segura e, finalmente, propõe modificação das condições de ensino enfatizando a importância da préescola e do ensino elementar como fundamentais para um desenvolvimento sadio do adolescente.

Este estudo mostrou o consumo de drogas entre os estudantes do ensino médio de um município do Estado de Santa Catarina (BR) e apontou que os números são preocupantes. Recomenda-se que seja replicado em outras cidades, pois Santa Catarina, possui uma diversidade muito grande de culturas e colonizações diferenciadas, desde pequenas cidades até de

\section{Colaboradores}

SL Sanceverino trabalhou na elaboração do projeto, na coleta, compilação e análise dos dados, e na redação final do artigo; JLC Abreu, na elaboração do projeto, na análise dos dados e na redação final do artigo.

\section{Referências bibliográficas}

Baus J, Kupek E \& Pires M 2002. Prevalência e fatores de risco relacionados ao uso de drogas entre escolares. Revista de Saúde Pública 36(1):40-46.

Bernardo M A 1995. Drogas no local de trabalho. Revista CIPA 192:30-42.

Bucher R 1992. Drogas e drogadição no Brasil. Artes M édica, Porto Alegre

Carlini-Contrim B 1998. Drogas na escola: prevenção, tolerância e pluralidade, pp. 19-30. In JG Aquino (org.) D rogas na escola: alternativas teóricas e práticas. Summus, São Paulo.

Cavalcante AM 1997. Drogas: esse barato sai caro. (2a ed.). Record-Rosa dos Tempos, Rio de Janeiro.

Colasanti B, M artin B, Craig CR \& Stitzel RE 1996. Farmacologia moderna. (5a ed.). Rio Guanabara Koogan S.A. Rio de Janeiro.

Galduróz JCF, N oto AR \& Carlini EA 1997. IV levantamento sobre 0 uso de drogas entre estudantes de 10 e 20 graus em 10 capitais brasileiras. Centro Brasileiro de Informações Sobre Drogas Psicotrópicas - CEBRID/Escola Paulista de M edicina, São Paulo.

Godoi AM, M uza GM, Costa M P \& Gama M LT 1991. Consumo de substâncias psicoativas por escolares da rede privada do Distrito Federal. Revista de Saúde Pública 25:150-156.

Gossop M \& Grant M 1990. Prevención y control del abuso de drogas. OMS, Espanha.

Grynberg H \& Kalina E 2002. Aos pais de adolescentes: viver sem drogas. (2a ed.). Record-Rosa dos Tempos, Rio deJaneiro. porte médio formadas por muitas origens migratórias. Além disso, há regiões turísticas que modificam de maneira significativa seu modo e estilo de vida em episódios sazonais.

Um dos limites deste estudo foi a possibilidade de sonegação de informações por parte dos participantes. Outro foi a superlotação de algumas das salas, com pouco espaço entreas carteiras, o que pode ter inibido o correto preenchimento do instrumento utilizado para coleta de dados. Por outro lado, dado que o questionário utilizado manteve $o$ anonimato dos informantes, parece ter havido favorecimento da sinceridade deles, ajudada pelas recomendações contidas no preâmbulo da aplicação que enfatizou, também, finalidade da pesquisa e seu caráter científico.
Kandel DB, Adler I \& Sudit M 1981. The epidemiology of adolescent drug use in France and Israel. American Journal of Public Health 71:256-65.

Muza GM , Bettiol H, Muccillo G \& Barbieri M A 1997. Consumo de substâncias psicoativas por adolescentes escolares de Ribeirão Preto, SP (Brasil). I - Prevalência do consumo por sexo, idade e tipo de substância. Revista de Saúde Pública 31(1):21-9.

Muza GM, Muccillo G, Bettiol H \& Barbieri M A 1997. Sobrea qualidade de um instrumento de pesquisa em consumo de substâncias psicoativas por adolescentes escolares. Revista de Saúde do Distrito Federal 8(4):17-24.

Oliveira ER \& Luís M AV 1996. Distúrbios relacionados ao álcool em um setor de urgências psiquiátricas. Ribeirão Preto, Brasil (1988-1990). Cadernos de Saúde Pública 12(2):171-179.

OPAS 1989. Boletin de la O ficina Sanitária Panamericana 107(6).

SENAD 2003. Informações sobre drogas. Disponível em <http://obid.senad.gov.br/OBID/Portal/index. jsp?ildPessoal uridica $=1>$

Souza DPO \& M artins DT 1995. O perfil epidemiológico do uso de drogas entre estudantes de lo e 20 graus da rede estadual de ensino de Cuiabá, Brasil, 1995. Cadernos Saúde Pública 14(2):391-400.

Artigo apresentado em 13/11/2003

Aprovado em 7/9/2004

Versão final apresentada em 12/7/2004 